\title{
Demonstration of a Novel Cladding Light Stripper Fabrication Method Based On Poly (Chloro-P-Xylene) Polymer Material
}

\author{
Yakup Midilli $^{1}$, Görkem Liman², Gökhan Demirel ${ }^{2}$, Bülend Ortaç ${ }^{1}$ \\ ${ }^{1}$ Bilkent University - UNAM National Nanotechnology Research Center and Institute of Materials Science and Nanotechnology, 06800, \\ Bilkent, Ankara, Turkey \\ ${ }^{2}$ Bio-inspired Materials Research Laboratory (BIMREL), Department of Chemistry, Faculty of Science, Gazi University, 06500, Besevler, \\ Ankara, Turkey
}

Cladding light stripper (CLS) is a key component for high power fiber laser systems to remove the unwanted light sources out of the system effectively. If they cannot be removed out of the system, the quality of the laser beam is affected severely. For that purpose, the fabrication of CLS has been investigated for years based on two main approaches. One of them is etching method $[1,2]$ and the other one is the coating method $[3,4]$. The CLS fabrication based on the recoated polymer has a problem of power scaling whereas the other one is more fragile since the fiber is deformed even though they are more capable of handling power. However, in this work we present a new method to coat a special polymer material on top of the fiber with Chemical Vapor Deposition (CVD) method with a high precision level in the range of nm scale.

The material coated on top of the fiber is Poly (chloro-p-xylene) [PPX], an exceptionally useful material for varying technological applications not only due to its superior electrical, thermal, and mechanical stability but moisture, chemical and dielectric properties. PPX deposition is a material independent technique, therefore, it can be coated on almost any material surface through vapor-phase deposition which is a simple, one step and environmental friendly process. In our work, the conformal coating of PPX films with varying thicknesses on optical fibers was carried out using a SCS-PDS2010 deposition system. In all depositions, a hydrophobic dichloro$[2,2]$-paracyclophane molecule was used as a starting monomer. The conformal polymer film deposition on samples was started by placing appropriate amounts of the monomer into an evacuated sublimator chamber. These monomers were then evaporated at about $175^{\circ} \mathrm{C}$ and converted to radicalic monomers by pyrolysis $\left(\sim 695^{\circ} \mathrm{C}\right)$. They were subsequently deposited and polymerized onto the fiber samples under vacuum ( $32 \mathrm{mTorr}$ ). The PPX film thickness on the samples was controlled by changing the amount of the precursor.
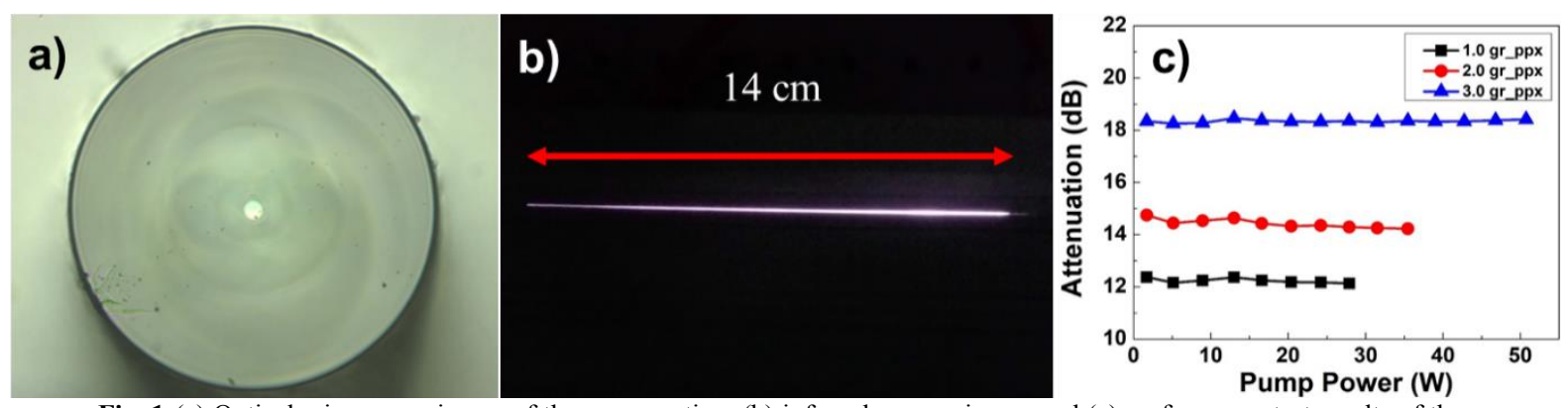

Fig. 1 (a) Optical microscope image of the cross section, (b) infrared camera image and (c) performance test results of the CLS with different material quantities

Since the thickness of the polymer material is highly controllable thanks to this so called technique and homogeneous all over the fiber sample as can be seen from the Fig. 1(a), the removal of the residual pump power is also homogenous all over the CLS region as shown in Fig. 1(b). the preliminary test results of the 3 different CLS samples having different material quantity has also been shown in Fig. 1(c) achieving up to $18 \mathrm{~dB}$ pump power suppression which is a good number for a CLS based on a polymer material.

\section{References}

[1] S. Z. Zou et al., "Cladding light stripper of high average stripped power density with high attenuation of $39 \mathrm{~dB}$ and low temperature rise," IEEE Photon. J., 10, 7100610, (2018).

[2] E. Yapar Yıldırım, A. Karatutlu, E. Teslime Balk, Y. Midilli, and B. Ortaç, "Combined method for the fabrication of high-power cladding light stripper using a buffered oxide etchant," Appl. Opt., 58, 6926-6933, (2019).

[3] Alexandre Wetter, Mathieu Faucher, Benoit Sévigny, "High power cladding light strippers," Proc. SPIE, 6873, 687327, (2008).

[4] W. Wang et al., "Method for stripping cladding light in the High power fiber laser," Opt. Commun., 287, 187-191, (2013). 